\title{
Bone Cement Treatment for Aneurysmal Bone Cyst in a Dog
}

\author{
Murat SARIERLER ${ }^{1)}$, Emre CULLU ${ }^{2)}$, Yakup YUREKLI ${ }^{3)}$ and Serap BIRINCIOGLU ${ }^{4)}$ \\ ${ }^{1)}$ Departments of Surgery and ${ }^{4)}$ Pathology, Faculty of Veterinary Medicine, ${ }^{2)}$ Department of Orthopedics and Traumatology and \\ ${ }^{3)}$ Nuclear Medicine Medical School, Adnan Menderes University, 09016 Aydin, Turkey
}

(Received 29 November 2003/Accepted 20 April 2004)

ABSTRACT. An eighteen month old female Doberman pinscher dog was referred to teaching hospital of Adnan Menderes University, Faculty of Veterinary Medicine with the complaint of right forelimb lameness for a month. On the basis of clinical, radiographical, scintigraphical, computed tomographical and histopathological findings, aneurysmal bone cyst was diagnosed. Surgical curettage and bone cement treatment were applied. The patient recovered after 12 months. This case proves that aneurysmal bone cyst, without osteolysis and/or damages to the surrounding tissues, may result in a good prognosis if curettage and treatment with bone cement are done. KEY WORDS: aneurysmal bone cyst, bone cement, canine.

J. Vet. Med. Sci. 66(9): 1137-1142, 2004

Aneurysmal bone cysts $(\mathrm{ABC})$ are expansile osteolytic lesions composed of large vascular sinusoids separated into compartments by thin-walled connective tissue stroma. These cysts are benign and non-neoplastic conditions that may be associated with locally aggressive growth, but does not metastasize [3]. The ideal therapy for dogs and cats with $\mathrm{ABC}$ has not been established [6]. The present case report described diagnosis and bone cement treatment of an ABC at the right proximal humeral region of an eighteen month old female Doberman pinscher dog, which recovered without initial complaints after the surgical treatment.

The patient, weighing approximately $30 \mathrm{~kg}$, was referred to our hospital with the complaint of right forelimb lameness for a month. Nonweight-bearing lameness was observed by the physical examination on the right forelimb and pain was noted by palpation of the proximal humeral region.

The complete blood cell count was within normal limits (red blood cell $6.67 \times 10^{6} / \mu l$, white blood cell $9.7 \times 10^{3} / \mu l$, packed cell volume $39.4 \%$, hemoglobin $13.1 \mathrm{~g} / \mathrm{d} l$ ) and the blood chemistry revealed no abnormalities (total protein $6.1 / \mathrm{d} l$, alanine aminotransferase 57 IU/L, aspartate aminotransferase $39 \mathrm{IU} / \mathrm{L}$, cholesterol $191 \mathrm{mg} / \mathrm{d} l$, blood urea nitrogen $17 \mathrm{mg} / \mathrm{d} l$, phosphorus $3.6 \mathrm{mg} / \mathrm{d} l$, calcium $10.5 \mathrm{mg} /$ $\mathrm{d} l$, sodium $147 \mathrm{mEq} / \mathrm{L}$, potassium $4.9 \mathrm{mEq} / \mathrm{L}$ and chloride $109 \mathrm{mEq} / \mathrm{L}$ ) except for a high level of alkaline phosphatase (ALP, 287 IU/L).

Radiographical examination of the right humerus (Fig. 1) revealed a destructive, expansile, hypodense lesion containing irregular septae in proximal metaphysiel region of humerus. This lesion caused cortical thinning starting from epiphysis. A suspicious cortical destruction at the posteriomedial side of the lesion was detected. No periosteal reaction and soft tissue invasion was observed. Moreover, there was a scapulohumeral luxation.

Whole body bone scintigraphy was performed after $3 \mathrm{hr}$ following intravenous injection of $7 \mathrm{mCi}{ }^{99 \mathrm{~m}} \mathrm{Tc}-\mathrm{MDP}$ (methylene diphosphonate) by using a single headed gamma camera (Siemens e-Soft, Hoffman Estates, Illinois, U.S.A.).
An increased osteoblastic activity was observed in the proximal part of right humerus. The central part of the lesion was hypoactive. There was no pathological activity in the other parts of the skeleton (Fig. 2). Distant and skip metastases were eliminated.

Computed tomographic (CT) sections without contrast revealed that there was an expansile hypodense lesion located in medullary area of the caput and collum of the right humerus causing cortical thinning. A cortical destruction of approximately $1 \mathrm{~cm}$ at the posterior side of humeral neck was also observed. The soft tissue-blood density $[(+30.3)-(+41.8)$ Hounsfield unite $]$ was obtained from various parts of the lesion by the density measurements. A homogenous structure was observed in the lesion. Periostal reaction and soft tissue invasion associated with lesion were not seen (Fig. 3).

A sanguineous fluid was detected by cyst aspiration. The bacteriological tests of the contents which were made on aerobic and anaerobic conditions at $37^{\circ} \mathrm{C}$ in $24-48 \mathrm{hr}$, revealed no bacterial growth. Cytological examination of the content showed some multinucleated giant cells, multiple spindle shaped fibroblasts, hemosiderin-laden macrophages and extravasated red blood cells. However there were not any findings of the inflammation.

On the basis of these findings, ABC diagnosis was made.

For the surgical treatment, the dog was anesthetized with $2 \mathrm{mg} / \mathrm{kg} /$ intravenously Xylazine $\mathrm{HCl}$ (Rompun, Bayer ${ }^{\circledR}$ ) and $10 \mathrm{mg} / \mathrm{kg} /$ intravenously ketamine $\mathrm{HCl}$ (Ketalar, Eczacibasi $\left.^{\circledR}\right)$ combination, following subcutaneously administration of $0.02 \mathrm{mg} / \mathrm{kg}$ atropine sulphate (Atropin, Vetas ${ }^{\circledR}$ ). By using lateral approach, cyst was reached and $2 \times 2 \mathrm{~cm}$ fenestration was applied on the lateral cortex (Fig. 4A). No instability sign due to scapulohumeral luxation was detected after dissection of proximal humerus. Sanguineous fluid was drained inside the cyst. Curettage was applied to all inner cortex of the cyst. The cyst was filled with bone cement (polymethylmethacrylate, CMW $1{ }^{\circledR}$, CMW Laboratories, Blackpool, England). We waited for $10 \mathrm{~min}$. to make the cement harden (Fig. 4B and Fig. 5). The wound 


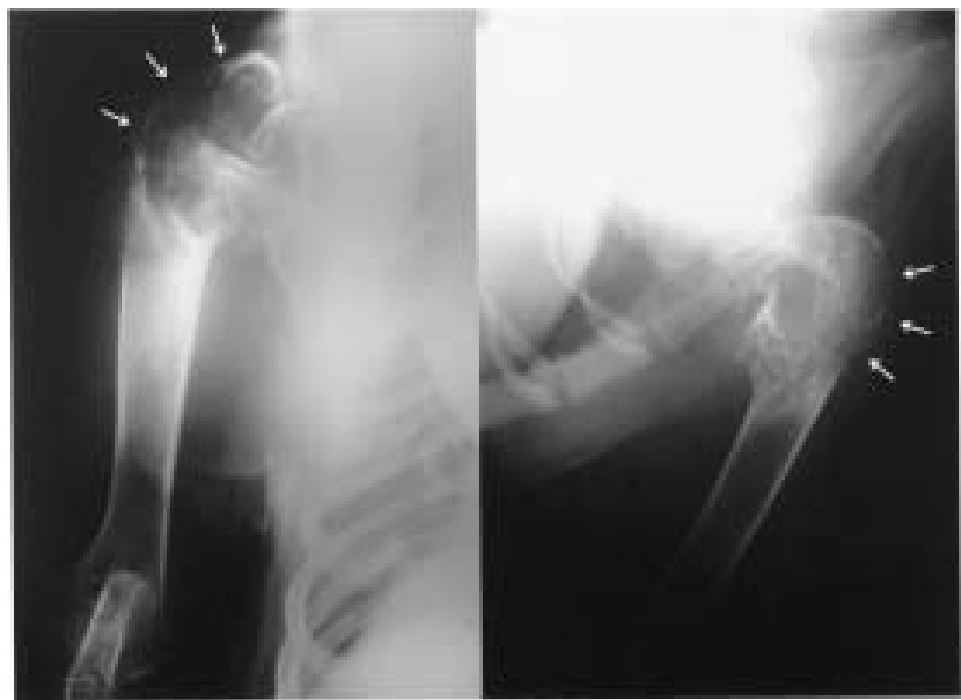

Fig. 1. Preoperative radiographic views of the aneurysmal bone cyst (arrows).
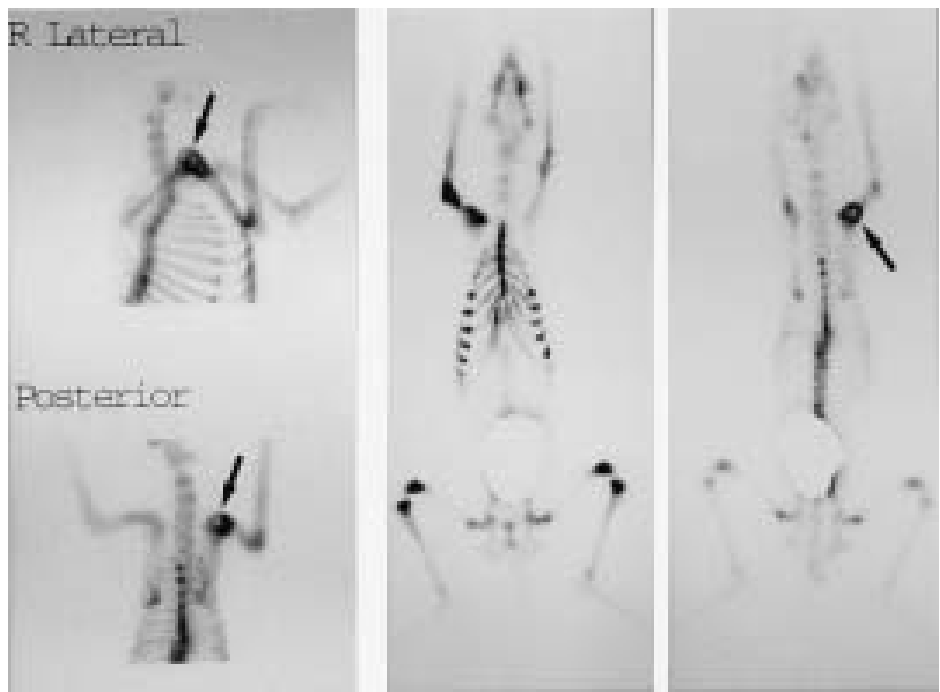

Fig. 2. Whole body bone scanning and spot views of the aneurysmal bone cyst (arrows).

was closed by the routine manner and bandage was applied. Sutures were taken a week later. Limb was left free after two weeks and the owner of the dog was taught passive exercise. Luxation was not reduced on that operation. Reduction of scapulohumeral luxation was planned with a sequential operation depending on histological and postoperative consequence.

The tissue samples obtained via curettage were submitted for histopathological examination. The samples were processed through alcohols and xylene, embedded in paraffin, sectioned at 5-6 $\mu \mathrm{m}$, and stained with Haematoxylin-Eosin (H.E.) and Mallory's trichrome [5]. Microscopically, granulation tissues, which were composed of numerous capillary proliferation, multiple spindle shaped fibroblasts, some multinucleated giant cells, hemosiderin-laden macrophages and extravasated red blood cells, were seen. Associated with this reaction, the surface of lumen was bloody and also contained a great number of erythrocytes, fibrin and leukocytes (Fig. 6). Hyalinization and calcification were identified at some parts of fibrous tissue whereas some other parts contained metaplastic cartilages (Fig. 7). In addition to these findings bone trabecules and granulation tissues were lying together and wall surrounded by fibrous capsule was seen on both areas.

ABCs in animals have been reported in dogs $[1,2,4,18$, $19,21,23-25]$, cats [3, 13, 27] and horses [11, 20, 26]. 


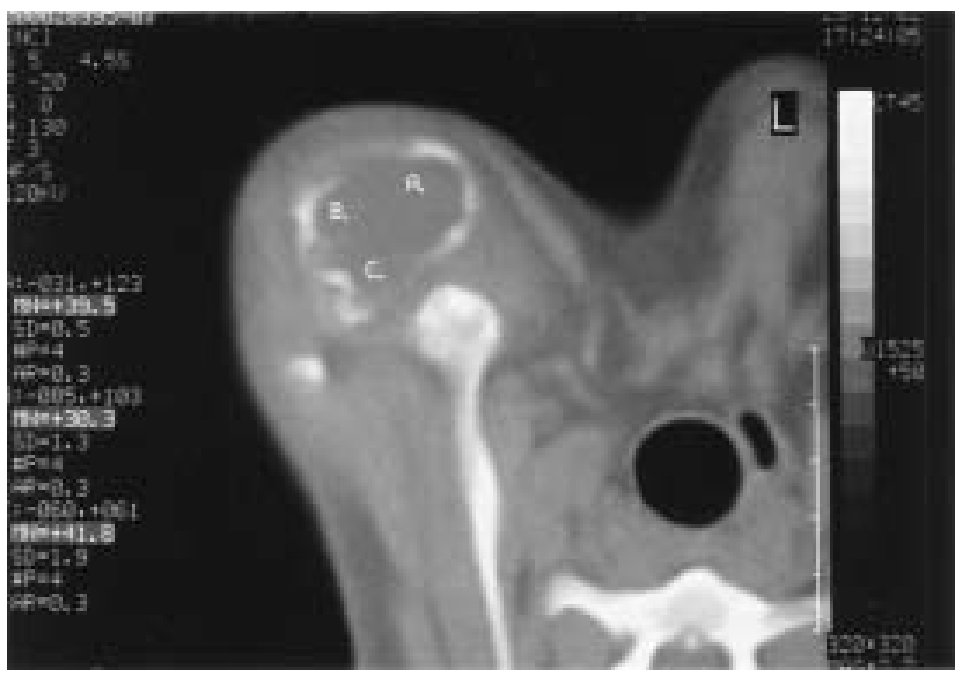

Fig. 3. Computed tomographic view of the lesion.

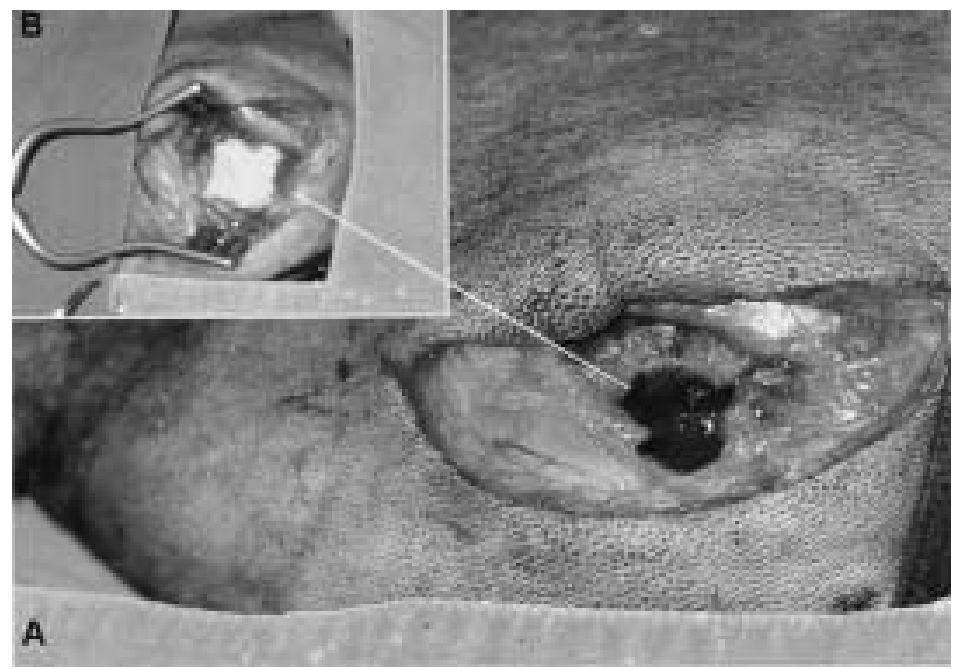

Fig. 4. Fenestration of $2 \times 2 \mathrm{~cm}$ on the lateral cortex of the humerus (A), the filling of the cyst with the bone cement (B).

ABCs are expansile osteolytic lesions composed of large vascular sinusoids separated into compartments by thinwalled connective tissue stroma. These cysts are benign and non-neoplastic conditions that may be associated with growth, but does not metastasize, and may be locally aggressive [3], but they may transform into a malignancy after surgical manipulation [1]. Differential diagnosis includes fibrosarcoma, osteolytic osteosarcoma, osteoblastic or giant cell tumor, and the unilocular membrane-lined simple bone cyst $[18,27]$. ABCs usually have a sharper junction between normal and abnormal bone, fibrosarcomas and osteolytic osteosarcomas. Giant cell tumors usually extend to the subchondral area of the epiphysis. Simple bone cysts usually differ by being unilocular, painless and by having bloodless contents unless a fracture has occurred
[27]. A definitive diagnosis of $\mathrm{ABC}$ depends on radiography and sufficient tissue biopsy. Radiographically, ABC appears as eccentric, osteolytic, expansile lesions at the metaphyses of long tubular bones [13, 18]. In our case, radiographically, destructive hypodens lesion, which included irregular septae, was seen and differential diagnoses for this lesion included $\mathrm{ABC}$, unicameral bone cyst and giant cell tumor.

In previous animal cases, there were not CT findings of $\mathrm{ABC}$. In this case, based on the data gathered with CT, soft tissue-blood density observed in the lesion suggested that the lesion was not an osteosarcoma. But irregular septae, which was seen in radiographs, could not be observed with CT.

There have been a few reports on the blood chemistry in 


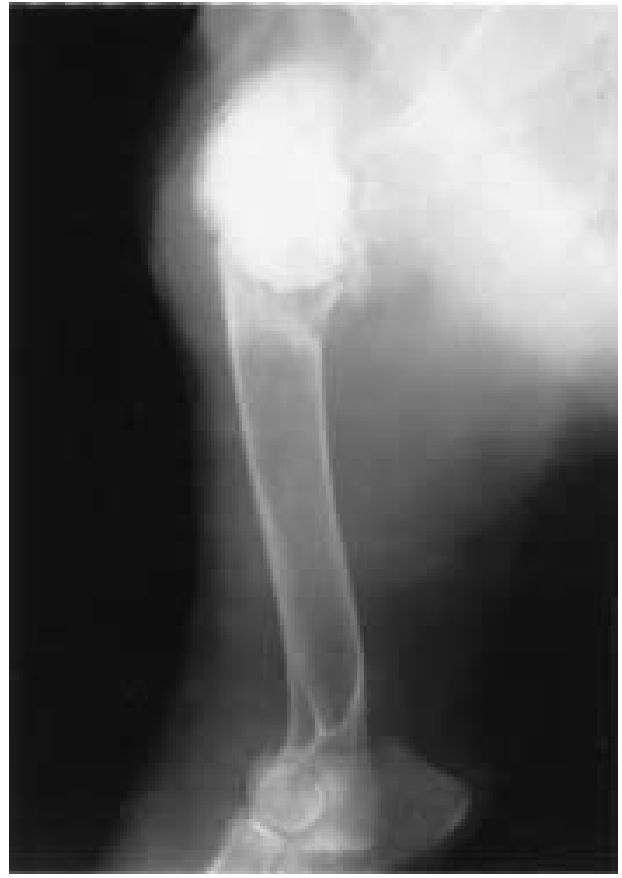

Fig. 5. Postoperative radiographic views of the aneurysmal bone cyst.

the previous $\mathrm{ABC}$ cases. They were also reported that, most of the blood chemical data were within normal ranges except for an increased ALP level [15]. It is thought that also in this case, the increase in ALP level is the result of the augmented osteolytic changes in ABC. In our study while in increase in ALP level is due to osteolytic changes in accordance with the other studies, no change in biochemical and blood analysis was observed.

In the animals, the pathogenesis and causes of the $\mathrm{ABC}$ are not yet well understood, however, it may be presumed similar to that in human cases [18]. Steiner and Rendano [26], by quoting other workers' results, pointed out of the following factors concerning the pathogenesis of $\mathrm{ABC} ; 1$ ) fibrous dystrophy of the bone, 2) hematoma caused by injury, 3) abnormal bleeding, and 4) bone tumour. They suggested that the ABC might develop secondarily as a sequel to the above-mentioned preexisting factors. And apart from their own equine case, they proposed a local soft tissue trauma without bone injury as an additional possibility [26]. Shimada and others [24] also described this case as one, which might have been caused secondarily from hemangiosarcoma, and in Doberman pinschers a hereditary predisposition has been reported [23]. Two different approaches could be considered for this case. First was the history of the dog that had a trauma happened 6 weeks before referring to our hospital. The second was the breed of the dog. The dog was a Doberman pinscher, which has hereditary predisposition for ABC.

Patients with bone cysts are known to have pain and lameness caused by the osteolysis of the bone or compression of surrounding soft tissues [3, 19, 21, 23, 24, 27]. Cases without these symptoms are rare $[4,26]$. In our case, cortical thinning at the humeral head and neck and minimal cortical destruction at the posterio-medial portion of the lesion were observed by radiological and CT examination. There was no any excessive soft tissue swelling.

The site of the lesion seems to be largely concerned with the prognosis of the condition. ABCs often affect the metaphysis or diaphysis of the long bone [18], where osteolysis is often recognized, and fracture may develop [19, 21, 23]. Because of the lack of understanding about the origin and growth of ABCs a variety of treatments has been described. Treatment options of ABC include irradiation alone, curettage, curettage augmented by the use of a high-speed bur, saucerization and bone marrow injection [9]. Resection of

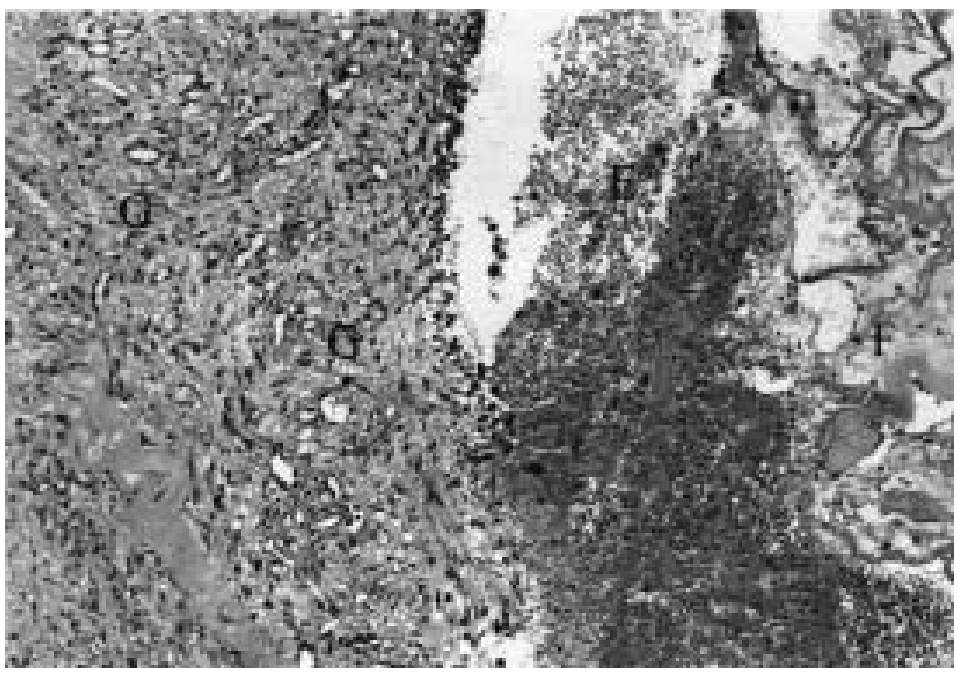

Fig. 6. The granulation tissue $(\mathrm{G})$ in wall of aneurysmal bone cyst. Erythrocytes (E), fibrin (F) and leucocytes in the lumen. Haematoxylin-Eosin $\times 53$. 


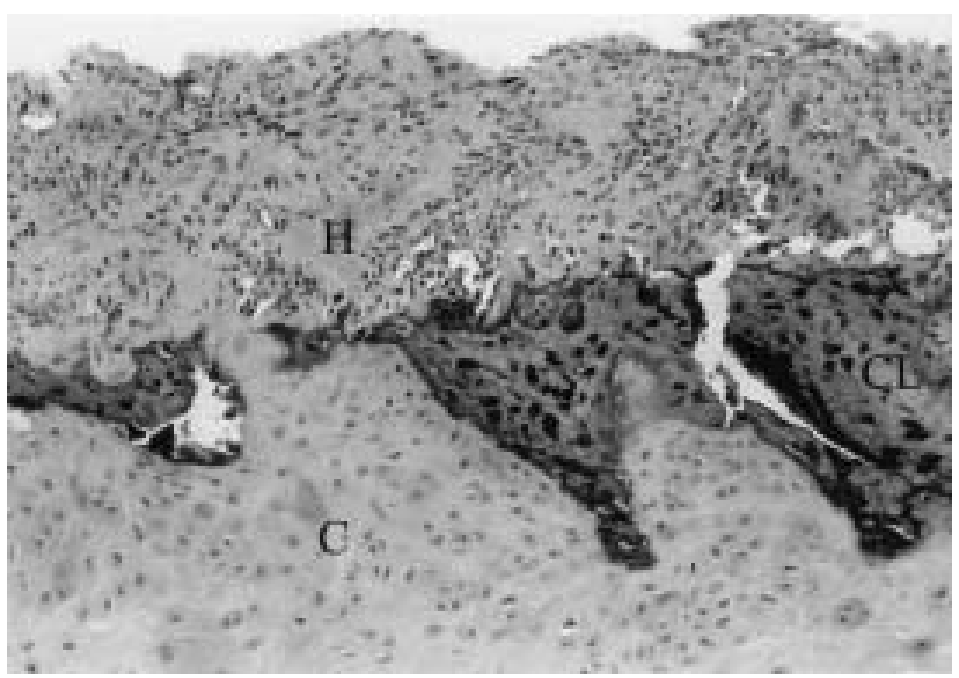

Fig. 7. Hyalinization $(\mathrm{H})$, calcification $(\mathrm{CL})$ and metaplastic cartilage $(\mathrm{C})$ on the wall of aneurysmal bone cyst. Haematoxylin-Eosin $\times 53$.

the tumor is advised when it is located in an expendable bone, such as fibula and rib [8]. In addition to the classical treatment options, adjuvants have been reported by several authors because of its recurrence risk. These adjuvants have included the use of cryotherapy, polymethylmethacrylate filling of the defect, alcohol injections, arterial embolization, and injections of steroids and calcitonin [8, 9]. Amputation $[19,24,27]$, or euthanasia [4, 13, 21, 25] has been reported in $\mathrm{ABC}$ for animals with suspicion of poor prognosis. Although the condition of the human cases is usually benign, and then curettage for the cyst and transplantation of a bone graft have been used for treatment for good prognosis [24], the ideal therapy for dogs and cats with $\mathrm{ABC}$ has not been established [6]. But left untreated, ABC may destroy a large part of the bone in which it originates or may invade surrounding soft tissue and adjacent bones [3]. In human patients, curettage alone and curettage with bone grafting have been associated with recurrence rates of 66 and $30 \%$ respectively, whereas partial or total excision improved the recurrence rate to between 0 and $23 \%$. Amputation has not been associated with any recurrences [22]. Because of high risk of local recurrence, adjunctive therapy, such as cementation, cryotherapy, or embolization, should be considered along with curettage. Cementation of the lesion with polymethylmethacrylate (bone cement) has been reported to be more effective than curettage and bone grafting alone [17]. Ozaki et al. [17] reported that the local recurrence rate after curettage and cementation was $17 \%$ and after curettage and bone graft was $37 \%$ in human patients. The cementation technique was simple and was associated with a low complication rate. The use of polymethylmethacrylate, although not new, has increased in popularity, for treatment of giant cell tumor of bone and ABC. It had approximately the same effect on local control as did cryotherapy. Komiya and Inoue [10] reported that heat greater than $60^{\circ} \mathrm{C}$ produced during the polymerization lasted for approximately $10 \mathrm{~min}$. According to the experiment of Leeson and Lippitt, [12] a polymethylmethacrylate related thermal effect can extend a few $\mathrm{mm}$ (from $2.5 \mathrm{~mm}$ in cancellous to $0.5 \mathrm{~mm}$ in cortical bone) into the surrounding tissue and decrease the recurrence rate in patients. This thermal effect is a main factor of the local control of the lesions. In a recent report from the Massachusetts General Hospital, O'donnell et al. [16] reported a local recurrence rate of $25 \%$ after cementation of giant cell tumors. This method is beneficial not only for giant cell tumors but also for ABCs. The difference of cumulative relapse free survival of people with curettage and cementation was significantly higher than that of patients with curettage and bone grafting.

The other advantage of cementation compared with the other methods is that bone cement takes the mechanical stress and prevents fracture. Some large lesions in high stress areas, such as in the cases reported by Marcove et al. [14] may be much more adequate for receiving cementation than bone grafting. The mechanical properties of the cement are a distinct advantage in these sites. In some cases, progressive remodeling and thickening of the cortical bone involving the cement also was observed [7]; these results indicate that the mechanical strength of bone cement may be increased by bone formation.

Excision arthroplasty has not been chosen for patient because of its permanent lameness result. In the present case, surgical curettage and treatment with bone cement of lesion located epiphysio-metaphysiel region was successful. Therefore we saved anatomical continuity of bone. After the operation, the patient was recovered. This result may suggest that $\mathrm{ABC}$ may result in a good prognosis without osteolysis and/or damages to the surrounding tissues, if curettage and treatment with bone cement is done successfully. 


\section{REFERENCES}

1. Barnhart, M. D. 2002. Vet. Surg. 31: 519-524.

2. Basher, A. V., Doige, C. E. and Presnell, K. R. 1988. J. Am. Anim. Hosp. Assoc. 24: 321-326.

3. Biller, D. S., Johnson, G. J., Birchard, S. J. and Fingland, R. B. 1987. J. Am. Vet. Med. Assoc. 190: 1193-1195,

4. Bowles, M. H. Y. and Freeman, K. 1987. J. Am. Anim. Hosp. Assoc. 23: 423-427.

5. Culling, F. A., Allison, R. T. and Barr, W. T. 1985. Cellular Pathology Technique, Butterworth \& Co., Ltd., London.

6. David, J. W. 1993. pp. 2213-2230. In: Textbook of Small Animal Surgery. 2nd. ed., (Slatter, D., ed.). W. B. Saunders Company, Philadelphia.

7. De Camargo, O. P., De Oliveira, N. R. B., Campos, F. R. and Croci, A. T. 1991. pp. 141-145. In: Limb Salvage-Major Reconstructions in Oncologic and Nontumoral Conditions (Langlais, F. and Tomeno, B. eds.). Springer, Berlin.

8. Gibbs, C. P. Jr., Hefele, M. C., Peabody, T. D., Montag, A. G., Aithal, V. and Simon, M. A. 1999. J Bone Joint Surg. [Am] 81: 1671-1678.

9. Hemmadi, S. S. and Cole, W. G. 1999. J. Pediatr. Orthop. 19: 540-542.

10. Komiya, S. and Inoue, A. 1993. Arch. Orthop. Trauma. Surg. 112: $51-55$.

11. Lamb, C. R. and Schelling, S. H. 1989. Equine Vet. J. 21: 130132.

12. Leeson, M. C. and Lippitt, S. B. 1993. Clin. Orthop. 295: 239245.

13. Liu, S. I-K., Dorfman, H. D. and Patnaik, A. K.1974. J. Small. Anim. Pract. 15: 141-156.
14. Marcove, R. C., Sheth, D. S., Takemoto, S. and Healey, J. H. 1995. Clin. Orthop. 311: 157-163.

15. Nomura, K. and Sato, K. 1997. J. Vet. Med. Sci. 59: 10271030.

16. O'donnell, R. J., Springfield, D. S., Motwani, H. K., Ready, J. E., Gebhardt, M. C. and Mankin, H. J. 1994. J. Bone Joint Surg. 76A: $1827-1833$.

17. Ozaki, T., Hillmann, A., Lindner, N. and Winkelmann, W. 1997. Clin. Orthop. 337: 240-248.

18. Palmer, N. 1992. pp. 138-In: Pathology of Domestic Animals, vol 1. 4th. ed. (Jubb, K. V. F., Kennedy, P. C. and Palmer, N. eds.) Academic Press, London.

19. Pernell, R. T., Dunstan, R. W. and DeCamp, C. E. 1992. J. Am. Vet. Med. Assoc. 201: 1897-1899.

20. Purdy, C. M. 1985. Vet. Clin. North. Am. Equine. Pract. 7: 22 24.

21. Renegar, W. R, Thornburg, L. P. and Burk, R. L. 1979. J. Am. Anim. Hosp. Assoc. 15: 191-195.

22. Ruiter, D. J., van Rijssel, T. G. and van der Velde, E. A. 1977. Cancer 39: 2231-2239.

23. Schrader, S. C., Burk, R. L. and Liu, S. K. 1983. J. Am. Vet. Med. Assoc. 182: 490-495

24. Shimada, A., Yanagida, M., Umemura, T., Tsukamoto, S. and Suganuma, T. 1996. J. Vet. Med. Sci. 58: 1037-1038.

25. Shiroma, J. T., Weisbrode, S. E., Biller, D. and Olmstead, M. 1993. J. Am. Anim. Hosp. Assoc. 29: 434-437.

26. Steiner, J. V. and Rendano, J. R. V. T. 1982. Cornell Vet. 72: 57-63.

27. Walker, M. A., Duncan, J. R., Shaw, J. W. and Chapman, W. 1975. J. Am. Vet. Med. Assoc. 167: 933-934. 